\title{
Thermal Treatment of Cerium Oxide and Its Properties: Adsorption Ability versus Degradation Efficiency
}

\author{
Pavel Janoš, ${ }^{1}$ Tomáš Hladík, ${ }^{1}$ Martin Kormunda, ${ }^{2}$ Jakub Ederer, ${ }^{1}$ and Martin Št’astný ${ }^{1}$ \\ ${ }^{1}$ Faculty of the Environment, University of Jan Evangelista Purkyně, Králova Výśina 7, 40096 Ústí nad Labem, Czech Republic \\ ${ }^{2}$ Faculty of Science, University of Jan Evangelista Purkyně, České Mládeže 8, 40096 Ústí nad Labem, Czech Republic \\ Correspondence should be addressed to Pavel Janoš; pavel.janos@ujep.cz
}

Received 21 January 2014; Revised 28 March 2014; Accepted 11 April 2014; Published 11 June 2014

Academic Editor: Zhimin Liu

Copyright (C) 2014 Pavel Janoš et al. This is an open access article distributed under the Creative Commons Attribution License, which permits unrestricted use, distribution, and reproduction in any medium, provided the original work is properly cited.

\begin{abstract}
Cerium oxide belongs to the most important heterogeneous catalysts, but its applicability as so-called reactive sorbent for the degradation of toxic chemicals was only recently discovered. For these purposes, cerium oxide is prepared by precipitation of insoluble cerium salts (carbonates) with a subsequent thermal decomposition. Properties of cerium oxide prepared from the carbonate precursor are strongly affected by the temperature during the calcination. Main physicochemical properties of cerium oxide (specific surface area, crystallinity, and surface chemistry) were examined in dependence on the calcination temperature. As the adsorptive properties of $\mathrm{CeO}_{2}$ are undoubtedly of great importance in the abovementioned applications, the adsorption ability was studied using an azo dye Acid Orange 7 (AO7) as a model compound. The highest sorption efficiency towards AO7 exhibited sorbents prepared at temperatures below $700^{\circ} \mathrm{C}$, which was attributed mainly to the presence of hydroxyl groups on the oxide surface. A strong correlation was found between an adsorption efficiency of cerium oxides and their degradation efficiency for organophosphate pesticide parathion methyl. The $>\mathrm{Ce}-\mathrm{OH}$ groups on the sorbent surface are responsible for the dye binding by the surface-complexation mechanism, and probably also for the nucleophilic cleavage of the $\mathrm{P}-\mathrm{O}$-aryl bond in the pesticide molecule.
\end{abstract}

\section{Introduction}

Cerium oxide is widely used in various branches of industry, especially in catalysis, where it plays a crucial role in socalled three-way catalysts for the control of gaseous exhaust emissions. In fact, $\mathrm{CeO}_{2}$ belongs to the most extensively studied catalytic materials and many other examples of its application in promoting various organic reactions can be found in the literature, such as oxidation of carbon monoxide [1], catalytic incineration of aromatic hydrocarbons [2], or mineralization (ozonation) of aniline [3]. Several authors reported on photocatalytic activity of $\mathrm{CeO}_{2}[4,5]$ and its ability to decompose synthetic dyes with efficiency higher than commonly used titanium oxide Degussa P25 [6]. In recent time, interactions of cerium oxide with biologically relevant molecules including ATP or DNA are mentioned in the literature together with potential applications in (nano)medicine [7-10]. These exciting properties and promising applications are mostly related to the nanocrystalline forms of cerium oxide-nanoceria, which may be prepared by many diverse synthetic routes including sol-gel methods, homogeneous hydrolysis in the presence of surfactants [1] or supported by microwave agitation [11], or hydrothermal synthesis [12, 13]. Conventional and well established precipitation methods have been successfully adopted to prepare nanostructured cerium compounds using oxalate, ammonium hydroxide [14, $15]$, ammonium carbonate, or bicarbonate $[6,16]$ as precipitants with subsequent calcination to obtain cerium oxide. It is generally accepted that the temperature during calcination plays a decisive role in governing the usability of the product, affecting directly its surface properties (specific area, presence of active sites), crystallinity, and other physicochemical characteristics [15]. In our previous work, we prepared highly reactive cerium oxide from carbonate precursor [17] and confirmed that its properties including reactivity may be finely tuned by the calcination temperature; most reactive sorbents were able to decompose dangerous organophosphate compounds (pesticides, nerve agents: soman and VX) 
within a few minutes. Other potential applications of cerium oxide as reactive sorbent are extensively studied now.

Although cerium oxide as such is only seldom used as adsorbent for removing pollutants from liquid effluents, the adsorption phenomena play necessarily the key role in catalytic and photocatalytic applications. Ji et al. [6] studied the adsorption of azo dye Acid Orange 7 on $\mathrm{CeO}_{2}$ in relation to its photocatalytic activity and concluded that superior adsorption properties of $\mathrm{CeO}_{2}$ in comparison with $\mathrm{TiO}_{2}$ cause its better photodegradation efficiency. An effect of $\mathrm{pH}$ on the sorption behaviour of $\mathrm{CeO}_{2}$ was studied in detail in this work. Effects of the synthetic conditions (synthesis in acidic and alkaline media) on the adsorption properties of cerium oxide were studied by Brigante and Schulz [18]. Nevertheless, the (liquid-phase) adsorption behaviour of various forms of cerium oxides prepared by various synthetic routes is still understood insufficiently. In the present work, we prepared a series of cerium oxides by calcination of cerium carbonate at various temperatures ranging from 200 to $1000^{\circ} \mathrm{C}$ and examined their sorptive properties towards Acid Orange 7 azo dye as the most popular model compound in photocatalytic applications. The adsorption kinetic dependencies were measured and possible mechanisms of adsorption were discussed. It was proven that the adsorption efficiency correlates closely with the degradation efficiency of $\mathrm{CeO}_{2}$ for organophosphate pesticide parathion methyl, even though both processes were studied in quite different media.

\section{Experimental}

2.1. Materials and Chemicals. Cerous nitrate, $\mathrm{Ce}\left(\mathrm{NO}_{3}\right)_{3} \cdot 6 \mathrm{H}_{2} \mathrm{O}$, was obtained from Sigma-Aldrich (Steinheim, Germany) as a reagent grade product with purity $99.9 \%$ (trace metal basis); ammonium bicarbonate, $\mathrm{NH}_{4} \mathrm{HCO}_{3}$, $99.5 \%$, was obtained from the same supplier. Acid Orange 7 (AO7) was supplied by Spolchemie (Usti nad Labem, Czech Republic) under the trade name Egacid Orange, C. I. number 15510. Organophosphate pesticide parathion methyl and its degradation product 4-nitrophenyl were obtained from Sigma-Aldrich as chromatographic standards. Unless stated otherwise, HPLC-grade organic solvents and deionized water were used to prepare the solutions including mobile phases for liquid chromatography.

The carbonate precursor was prepared by precipitation of an aqueous solution of cerous nitrate $(0.2 \mathrm{~mol} / \mathrm{L})$ with an excess of ammonium bicarbonate $(0.5 \mathrm{~mol} / \mathrm{L})$ under stirring; the completeness of the precipitation was checked by reaction with oxalic acid. After adding the last portion of ammonium bicarbonate, the agitation continued for one more hour and the precipitate was left until the next day. Then, the precipitate was separated by filtration, washed with water, and dried overnight at $110^{\circ} \mathrm{C}$. The prepared carbonate did not have an exact formula; it was a mixture of normal and basic carbonates. Using the X-ray diffraction analysis, a crystalline phase of the $\mathrm{Ce}_{2} \mathrm{O}\left(\mathrm{CO}_{3}\right)_{2} \cdot n \mathrm{H}_{2} \mathrm{O}$ type was identified. In addition, further unidentified crystalline and amorphous components were present. The $\mathrm{CeO}_{2}$ samples were prepared from the carbonate by calcination at predetermined temperatures in the range $200-1000^{\circ} \mathrm{C}$ for two hours in a muffle furnace.

2.2. Methods of Characterization. A scanning electron microscope (SEM) Tescan Vega LSU was used to examine the sorbent. X-ray diffraction (XRD) measurements were carried out on a MPD 1880 diffractometer (Philips). The crystallite sizes were calculated from diffraction line broadening using the Scherrer formula [19]:

$$
a=\frac{K \lambda}{\beta \cos \theta},
$$

where $K$ is the shape factor, $\lambda$ is the wavelength of the applied radiation, $\beta$ is the broadening of the diffraction line, and $\theta$ is the diffraction angle. The Scherrer Calculator from the X-Pert HighScore Plus SW package was used for these calculations. Specific surface area of the sorbents was measured by the BET method ( $\mathrm{N}_{2}$ adsorption) with a Sorptomatic 1900 Carlo Erba instrument. Surface composition of the sorbents was investigated by X-ray photoelectron spectroscopy (XPS). The XPS instrument was based on the SPECS Phoibos 100 and XR50 components. Al $K \alpha$ spectral line (photon energy $1486.6 \mathrm{eV}$ ) was used to induce the photoelectron emission. High resolution spectra of $\mathrm{Ce} 3 \mathrm{~d}$ and $\mathrm{O}$ 1s were recorded to obtain the information on the chemical bonding statistics of the elements. The software CasaXPS was used for the spectra computer processing. Diffuse reflectance Fourier transform spectroscopy (DRIFTS) was employed to measure IR spectra using a Nicolet Impact $400 \mathrm{D}$ spectrometer; the spectra were recorded over the range of approximately $4000-500 \mathrm{~cm}^{-1}$ and expressed in a transmittance mode. The DRIFT spectra were collected at $16 \mathrm{~cm}^{-1}$ resolution, and each spectrum was averaged over 512 scans. Spectra analyses were performed using the OMNIC software (Thermo Nicolet, Madison).

2.3. Sorption Experiments. Kinetic sorption experiments were carried out by shaking a known amount of the sorbent (typically $0.5 \mathrm{~g}$ ) with $100 \mathrm{~mL}$ of the solution containing desired concentrations of the dye (typically $0.1 \mathrm{mmol} / \mathrm{L}$ ). The dye solution together with the sorbent was agitated in a closed PE bottle using a horizontal shaker LT 2 (Kavalier, Sázava, Czech Republic) with an intensity of agitation $200 \mathrm{~min}^{-1}$. In the predetermined time intervals (0-100 $\mathrm{min})$, small volumes of the solution were taken by a micropipette and centrifuged immediately to separate the sorbent particles. The dye concentration was determined by HPLC.

2.4. Degradation of Organophosphate Pesticides. The testing procedure was derived from those used to examine chemical warfare degradation and is described in detail in our previous paper [17]. In this procedure, constant amounts (50 mg) of the sorbent were weighed into a series of glass vials (Supelco, $4 \mathrm{~mL}$ ), and an exact volume $(150 \mu \mathrm{L})$ of the pesticide solution $\left(6660 \mathrm{mg} \mathrm{L}^{-1}\right)$ in heptane was added to each vial (corresponding to a dosage of $1 \mathrm{mg}$ of pesticide per $50 \mathrm{mg}$ of sorbent). The vials were sealed with caps and covered with aluminum foil to protect the reaction mixture from sunlight. 
At predetermined time intervals $(0.5,8,16,32,64,96$, and $128 \mathrm{~min})$, the reaction was terminated by an addition of 2 propanol $(2 \mathrm{~mL})$, and the sorbent was immediately separated by centrifugation ( $4000 \mathrm{rpm}$ for $7 \mathrm{~min}$ ). The supernatant was decanted and transferred to a $50 \mathrm{~mL}$ volumetric flask and then the sorbent was redispersed in $4 \mathrm{~mL}$ of methanol and centrifuged again. The extraction of the sorbent with methanol was repeated three times. All the supernatants were combined into one volumetric flask, made up to the mark with methanol, and analyzed immediately by liquid chromatography (HPLC), gas chromatography with mass spectrometric detection (GC-MS), and UV/Vis spectrometry. All degradation experiments were conducted at the laboratory temperature of $22 \pm 1^{\circ} \mathrm{C}$ in an air conditioned box. In each series of measurements, several types of quality control experiments were performed: procedure blank experiments with the sorbent and solvents without the presence of pesticide and 2-3 experiments with various concentrations of pesticide in working solutions without the presence of sorbent. Using a spiked sample, the recovery of 4-nitrophenol as the main degradation product of parathion methyl was examined.

2.5. Analyses and Data Evaluation. Liquid chromatography (HPLC) in a reversed-phase ion-interaction mode was used to determine the dye concentrations and for the detection of potential degradation products [20]. The liquid chromatograph consisted of the high pressure pump LaChrom L7100 (Merck/Hitachi, Hitachi High-Technol. Corp., Tokyo, Japan), the Rheodyne 7125 injection valve with $20 \mu \mathrm{L}$ sampling loop, vacuum degasser, and the variable wavelength UV detector LaChrom L-7400 (Merck/Hitachi) operating at $250 \mathrm{~nm}$. Chromatographic separations were carried out on the Hibar column $125 \times 4 \mathrm{~mm}$ packed with octadecylbonded stationary phase Purospher STAR, RP-18e, $5 \mu \mathrm{m}$ (Merck, Darmstadt, Germany), with mobile phase consisting of $75 \%(\mathrm{v} / \mathrm{v})$ methanol and $25 \%(\mathrm{v} / \mathrm{v}) 0.2 \mathrm{mmol} / \mathrm{L}$ tetrabutylammonium hydrogensulfate; the flow rate was $1 \mathrm{~mL} / \mathrm{min}$. Concentrations of parathion methyl and 4-nitrophenol were determined by HPLC using the same instrumentation with the Luna column (Phenomenex, Torrance, CA, USA) 150 $\times 4.6 \mathrm{~mm}$, packed with PFP stationary phase, $5 \mu \mathrm{m}$. The composition of mobile phase was methanol (HPLC-grade, Labscan, Dublin, Ireland)/water 80/20 (v/v), at a flow rate $1 \mathrm{~mL} / \mathrm{min}$. A gas chromatograph Varian GC 3800 coupled with an ion trap mass spectrometer (Varian 4000) and a fused silica capillary column (VF-5; $20 \mathrm{~m} \times 0.25 \mathrm{~mm} \times 0.25 \mu \mathrm{m})$, all from Varian (Varian Inc., Palo Alto, USA), were used to confirm the identity of the target analytes.

MS Excel and OriginPro 8.5 (OriginLab Corp., USA) software were used for calculations and data evaluations; VESTA 3 SW [21] was used to visualize some crystal and molecular structures.

\section{Results and Discussion}

3.1. Characterization of $\mathrm{CeO}_{2}$. The dried cerous carbonate as the precursor for the $\mathrm{CeO}_{2}$ preparation was a finely crystalline powder containing (according to the X-ray diffraction and chemical analysis) a mixture of amorphous and poorly crystalline normal and basic carbonates, whose exact chemical composition (formula) could not be established. As can be seen from the SEM image (Figure 1(a)), the cerous carbonate consisted of clusters of thin plates of irregular shapes with a characteristic diameter of several micrometers and a thickness in a submicron range. It was observed that cerium oxides prepared by calcination of the carbonate precursor retained its morphology; see Figure $1(\mathrm{~b})$. As confirmed by $\mathrm{X}$-ray diffraction, a single crystalline phase corresponding to pure $\mathrm{CeO}_{2}$ predominated in all the samples annealed at temperatures above $200^{\circ} \mathrm{C}$, although several minor peaks were observed in some diffractograms, corresponding probably to residual carbonaceous species. Examples of selected XRD patterns are given in Figure 2; the positions of the main peaks and their relative intensities matched exactly with the simulated ones. Similar patterns were obtained for the other cerium oxides with respect to the peak positions and intensity. As can be seen, the peak shapes changed gradually in dependence on the calcination temperature; with increasing calcination temperature, the diffraction peaks narrowed, witnessing that the crystallites grew and acquired a more ordered structure. The sizes of the crystallites calculated from the peak broadening using the Scherrer formula (1) are listed in Table 1 together with some other physicochemical characteristics. The crystallite size changes noticeably (increases) with an increasing temperature of calcination, whereas the surface area decreased; the most dramatic changes occurred in the temperature range of ca. $400-700^{\circ} \mathrm{C}$.

The XPS measurements revealed significant differences in the surface chemistry for the $\mathrm{CeO}_{2}$ samples annealed at different temperatures. The samples annealed at temperatures above $400^{\circ} \mathrm{C}$ had a dominant single $\mathrm{O}$ 1s peak at a binding energy of $530 \mathrm{eV}$ representing $\mathrm{CeO}_{2}\left(\mathrm{Ce}^{4+}\right)$ and a shoulder at a higher binding energy-about $533 \mathrm{eV}-$ representing hydroxyl $(-\mathrm{OH})$ groups on the surface of the sorbents (Figure 3(a)). The samples annealed at temperatures below $500^{\circ} \mathrm{C}$ had an additional distinct peak at about $532 \mathrm{eV}$, which disappeared with increasing calcination temperatures (Figure 3(b)); this peak was associated with $\mathrm{Ce}^{3+}$ ions. It may be concluded that an abundance of $\mathrm{O}-\mathrm{Ce}^{3+}$ and the hydroxyl groups decreased at higher calcination temperatures (Figure 3(c)). The small increase in abundance of $\mathrm{O}-$ $\mathrm{Ce}^{3+}$ components can be influenced by Shirley background or lower signal intensity.

The observations of $\mathrm{O}-\mathrm{Ce}^{3+}$ in $\mathrm{O} 1$ s peaks were confirmed also by an analysis of the $\mathrm{Ce} 3 \mathrm{~d}$ peaks. The electronic structure of $\mathrm{CeO}_{2}$ is characterized by unoccupied $4 \mathrm{f}$ states of $\mathrm{Ce}^{4+}\left(4 \mathrm{f}^{0}\right)$, while $\mathrm{Ce}^{3+}$ has a $4 \mathrm{f}^{1}$ configuration. The different $4 \mathrm{f}$ configurations for $\mathrm{Ce}^{4+}$ and $\mathrm{Ce}^{3+}$ result in different core levels and also valence bands. The XPS spectrum of partially reduced cerium in Ce $3 \mathrm{~d}$ consists of three $3 \mathrm{~d} 3 / 2-3 \mathrm{~d} 5 / 2$ spin-orbitsplit doublets representing different $4 \mathrm{f}^{0}\left(\mathrm{Ce}^{4+}\right)$ configurations (solid lines in Figure 4(a)) in the photoemission final state, and two other doubles represent $4 \mathrm{f}^{1}\left(\mathrm{Ce}^{3+}\right)$ states (dotted lines in Figure 4(a)). 


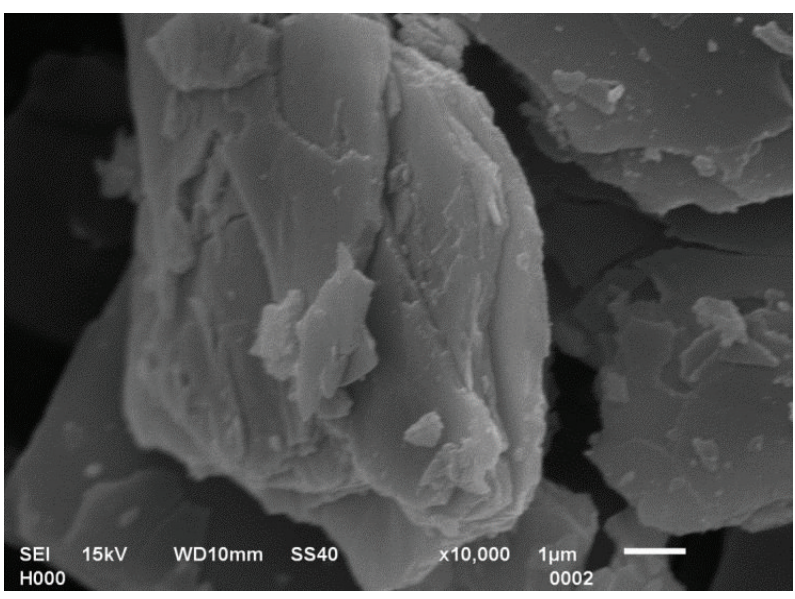

(a)

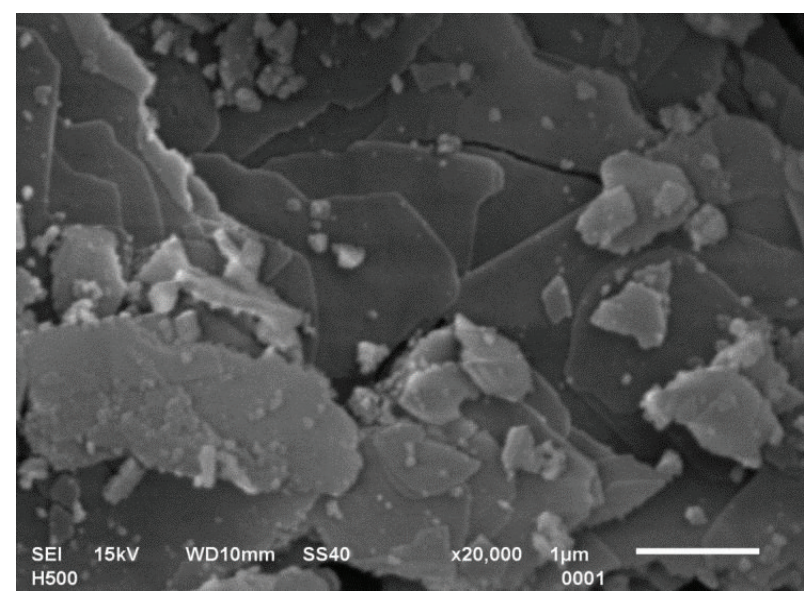

(b)

Figure 1: (a) SEM images of carbonate precursor dried at $110^{\circ} \mathrm{C}$; (b) $\mathrm{CeO}_{2}$ annealed at $500^{\circ} \mathrm{C}$.

TABLE 1: Properties of cerium oxide prepared by annealing at various temperatures.

\begin{tabular}{|c|c|c|c|c|}
\hline Annealing temperature $\left({ }^{\circ} \mathrm{C}\right)$ & Specific surface area $\left(\mathrm{m}^{2} / \mathrm{g}\right)$ & Crystallite size $(\mathrm{nm})$ & Point of zero charge & $\mathrm{pH}_{\text {changes }}^{\mathrm{a}}$ \\
\hline 200 & 153 & 13 & 5.5 & $4.87 \rightarrow 7.68$ \\
\hline 300 & 148 & 15 & 5.7 & $3.43 \rightarrow 8.22$ \\
\hline 400 & 138 & 12 & 6.0 & $3.86 \rightarrow 8.57$ \\
\hline 500 & 112 & 13 & 5.7 & $3.95 \rightarrow 7.64$ \\
\hline 600 & 62 & 26 & 6.0 & $4.15 \rightarrow 8.45$ \\
\hline 700 & 13 & 69 & 5.8 & $3.67 \rightarrow 6.22$ \\
\hline 800 & 3.3 & 205 & 6.0 & $4.72 \rightarrow 6.44$ \\
\hline 900 & 1.5 & 205 & 6.1 & $4.74 \rightarrow 5.22$ \\
\hline 1000 & ND & 205 & 6.1 & $4.29 \rightarrow 5.22$ \\
\hline
\end{tabular}

${ }^{a} \mathrm{pH}$ changes during the sorption of $\mathrm{AO} 7$ on $\mathrm{CeO}_{2}$. Initial concentration of $\mathrm{AO} 70.1 \mathrm{mmol} / \mathrm{L}$; sorbent : solute ratio $10: 1$ (g/L); equilibrating time $120 \mathrm{~min}$.

In more detail, the highest binding energy peaks, $\mathrm{u}^{\prime \prime \prime}$ and $\mathrm{v}^{\prime \prime \prime}$ located at about $916.9 \mathrm{eV}$ and $898.5 \mathrm{eV}$, respectively, are results of the $\mathrm{Ce} 3 \mathrm{~d}^{9} 4 \mathrm{f}^{0} \mathrm{O} 2 \mathrm{p}^{6}$ final state. The satellite peak $\mathrm{u}^{\prime \prime \prime}$ associated with the Ce $3 \mathrm{~d} 3 / 2$ is characteristic of the presence of $\mathrm{Ce}^{4+}$. The lowest binding energy states $\mathrm{u}, \mathrm{v}, \mathrm{u}^{\prime \prime}$, and $\mathrm{v}^{\prime \prime}$, respectively, located at $901.1 \mathrm{eV}, 882.7 \mathrm{eV}, 907.3 \mathrm{eV}$, and $888.8 \mathrm{eV}$, are the results of the Ce $3 \mathrm{~d}^{9} 4 \mathrm{f}^{2} \mathrm{O} 2 \mathrm{p}^{4}$ and Ce $3 \mathrm{~d}^{9} 4 \mathrm{f}^{1}$ O $2 \mathrm{p}^{5}$ final states.

The $\mathrm{Ce}^{3+}$ oxides have Ce $3 \mathrm{~d} 3 / 2,5 / 2$ spectra composed of two multiplets. The highest binding energy peaks, $\mathrm{u}^{\prime}$ and $\mathrm{v}^{\prime}$ located at about $903.4 \mathrm{eV}$ and $885.0 \mathrm{eV}$, respectively, are the results of the $\mathrm{Ce} 3 \mathrm{~d}^{9} 4 \mathrm{f}^{1} \mathrm{O} 2 \mathrm{p}^{6}$ final state. The lower binding energy states, $u^{0}$ and $v^{0}$, respectively, located at $899.6 \mathrm{eV}$ and $881.1 \mathrm{eV}$, are the results of the Ce $3 \mathrm{~d}^{9} 4 \mathrm{f}^{2}$ O $2 \mathrm{p}^{5}$ final state. The XPS investigations of the Ce $3 \mathrm{~d}$ peaks indicate that the $\mathrm{Ce}^{3+}$ and $\mathrm{Ce}^{4+}$ species can be distinguished with line shapes corresponding to various final states (see Figure 4(a)).

With increasing calcination temperature, the Ce $3 \mathrm{~d}$ peaks decreased in the amounts of doublets corresponding to the $4 \mathrm{f}^{1}\left(\mathrm{Ce}^{3+}\right)$ states in components $\mathrm{u}^{\prime}, \mathrm{v}^{\prime}, \mathrm{u}^{0}$, and $\mathrm{v}^{0}$ (see Figure 4(b)), where the observed decrease was from about 6 to $4 \%$ for $\mathrm{u}^{\prime}$. Although the signals were rather low due to the surface roughness of the samples, the overall tendencies of the $\mathrm{O} 1$ s peaks and the $\mathrm{Ce} 3 \mathrm{~d}$ peaks support the conclusion of a $\mathrm{Ce}^{3+}$ decreasing trend at higher calcination temperatures above $200^{\circ} \mathrm{C}$ (Figure 3(c)). The Ce $3 \mathrm{~d}$ peak taken on samples prepared at calcination temperatures below $300^{\circ} \mathrm{C}$ cannot be successfully deconvoluted without $\mathrm{Ce}^{3+}$ components.

The reduction of $\mathrm{Ce}^{3+}$ states was observed in Ce $3 \mathrm{~d}$ and also in $\mathrm{O} 1 \mathrm{~s}$ peaks. The $\mathrm{O} / \mathrm{Ce}$ ratio decreased with increasing calcination temperature (Figure 5). The results demonstrate the $\mathrm{O} / \mathrm{Ce}$ overstoichiometry for samples prepared at calcination temperatures below $400^{\circ} \mathrm{C}$; see the right axis in Figure 5 on. This is probably related to the presence of the $-\mathrm{OH}$ groups bonded to the ceria surface, a common phenomenon observed with metal oxides originated from wet syntheses. Taking into account the presence of the $-\mathrm{OH}$ groups in the oxygen balance, the $\mathrm{O} / \mathrm{C}$ ratio suggests the understoichiometric nature of the cerium oxides; see also a dotted line in Figure 5.

The infrared spectra confirmed the presence of hydroxyl groups and carbonate species in the samples annealed at various temperatures. Broad bands in the region of 400$700 \mathrm{~cm}^{-1}$ were attributed to the $\mathrm{Ce}-\mathrm{O}$ stretching vibration. The band at $1630 \mathrm{~cm}^{-1}$ was ascribed to the bending mode of hydroxyl groups of adsorbed water, whereas the relatively 

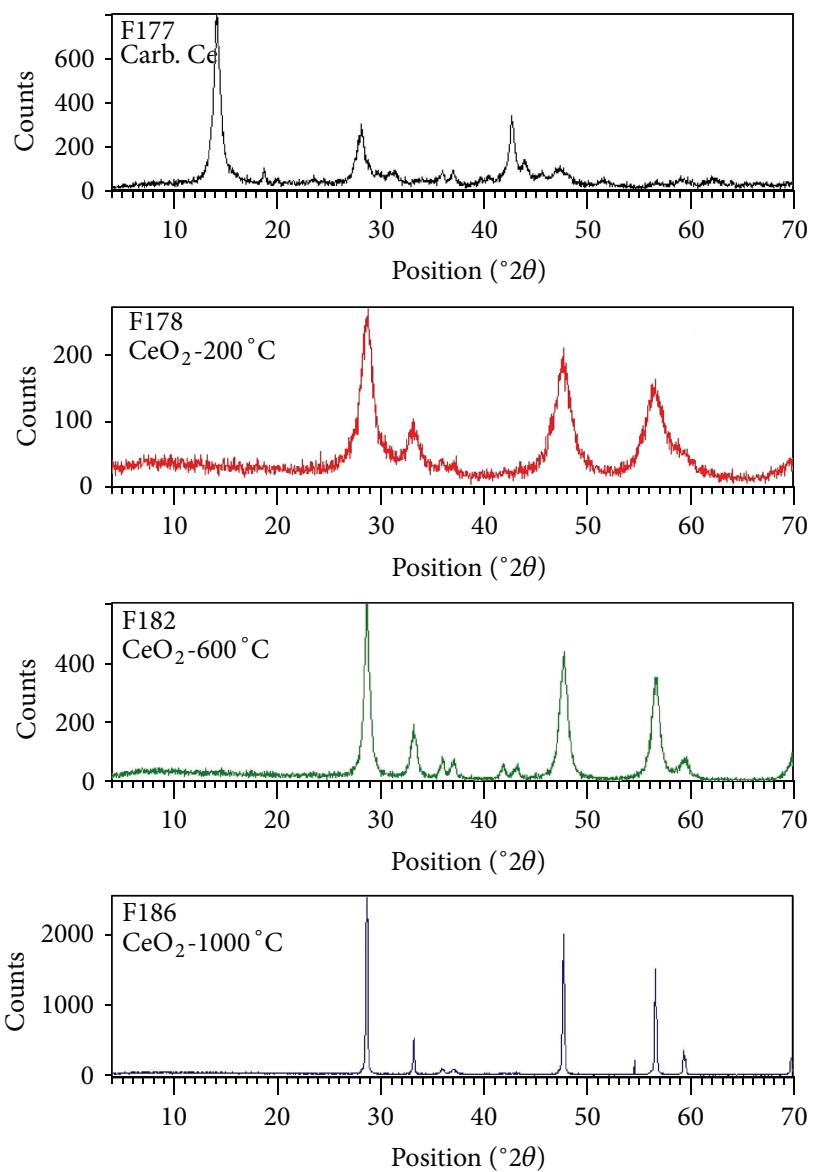

(a)

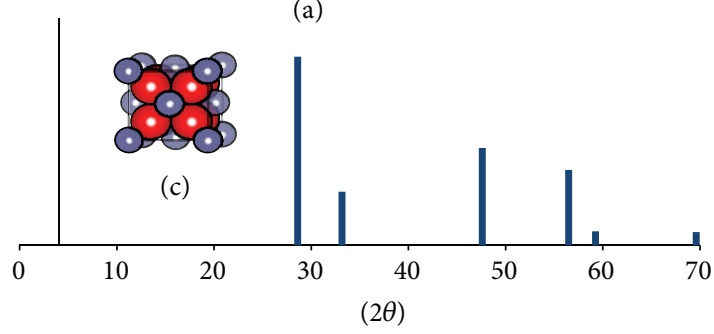

(b)

FIGURE 2: (a) XRD patterns of cerium carbonate (precursor) and cerium oxides annealed at 200,600 , and $1000^{\circ} \mathrm{C}$ (from top to bottom). (b) Peak positions and relative intensities calculated from structure parameters using VESTA 3 SW [21], input data from PDF 81-0792. (c) Fluorite-like cubic structure of $\mathrm{CeO}_{2}$.

strong absorption bands at around $850-1550 \mathrm{~cm}^{-1}$ were assigned to the adsorbed carbonate species. The absorption bands at $3000-3500 \mathrm{~cm}^{-1}$ weakened with increasing calcination temperature, but they did not disappear completely, indicating the persistence of the structural $-\mathrm{OH}$ groups. A complete dehydration and decarbonation was observed at temperatures above $800^{\circ} \mathrm{C}$.

3.2. Adsorption of AO7 on Cerium Oxide. The kinetic dependencies for the sorption of $\mathrm{AO} 7$ on the $\mathrm{CeO}_{2}$ samples annealed at various temperatures are shown in Figure 6. To
TABLE 2: Parameters of the pseudo-first-order kinetic equation for the sorption of $\mathrm{AO} 7$ on $\mathrm{CeO}_{2}$ annealed at different temperatures.

\begin{tabular}{lcccc}
\hline $\begin{array}{l}\text { Annealing } \\
\text { temperature } \\
\left({ }^{\circ} \mathrm{C}\right)\end{array}$ & $q_{\infty}(\mathrm{mmol} / \mathrm{g})^{\mathrm{a}}$ & $k_{1}\left(\mathrm{~min}^{-1}\right)^{\mathrm{a}}$ & $R^{2}$ & RSS \\
\hline 200 & $0.283(0.003)$ & $0.422(0.022)$ & 0.9961 & 0.0004 \\
300 & $0.276(0.004)$ & $0.446(0.035)$ & 0.9916 & 0.0005 \\
400 & $0.273(0.005)$ & $0.584(0.070)$ & 0.9827 & 0.0010 \\
500 & $0.312(0.010)$ & $0.384(0.069)$ & 0.9517 & 0.0039 \\
600 & $0.326(0.008)$ & $0.540(0.091)$ & 0.9643 & 0.0030 \\
700 & $0.172(0.005)$ & $0.441(0.075)$ & 0.9592 & 0.0002 \\
800 & $0.079(0.002)$ & $0.475(0.085)$ & 0.9570 & 0.0006 \\
900 & $0.060(0.004)$ & $0.177(0.059)$ & 0.8394 & 0.0026 \\
1000 & $0.031(0.008)$ & $0.158(0.019)$ & 0.9775 & 0.0005 \\
\hline
\end{tabular}

${ }^{\mathrm{a}}$ Standard errors given in parentheses.

evaluate the experimental dependencies, the pseudo-firstorder (PFO) model was used. It was shown that this model, although empirical by its nature, approximates well more rigorous theoretical approaches based, for example, on a statistical rate theory [22]. The PFO adsorption rate equation may be expressed as

$$
\frac{d q_{t}}{d t}=k_{1}\left(q_{\infty}-q_{t}\right)
$$

where $q_{t}$ is the amount adsorbed at time $t, q_{\infty}=q_{t}(t \rightarrow \infty)$, and $k_{1}$ is the PFO rate constant. An integral form of (2) is

$$
q_{t}=q_{\infty}\left(1-e^{-k_{1} t}\right) .
$$

The model parameters obtained by a method of nonlinear regression are listed in Table 2 . As can be seen from Figure 6, the sorption of $\mathrm{AO} 7$ on $\mathrm{CeO}_{2}$ is a quite rapid process approaching equilibrium within a time frame of minutes rather than hours; typical half-times were 1.2 to $1.6 \mathrm{~min}$, which is sufficiently fast for potential applications in photocatalysis.

The sorption efficiencies differed markedly for the samples annealed at different temperatures. Using the $q_{e}$ value as an estimator of the sorption efficiency, the temperature dependence was expressed in Figure 7(a). The highest sorption efficiency was observed for the samples annealed at lower temperatures with a maximum temperature lying at ca. $500-600^{\circ} \mathrm{C}$ and with a sudden drop at temperatures above $700^{\circ} \mathrm{C}$. To examine the nature of the $\mathrm{AO} 7$ binding on $\mathrm{CeO}_{2}$, the loaded sorbent was leached with various solvents and solutes; the results are shown in Figure 8. The lowest extraction (desorption) efficiency exhibited aprotic organic solvents, both nonpolar (heptane) and polar (acetonitrile), whereas a desorption efficiency of protic organic solvent (methanol) was comparable with that of water. Obviously the solvent-solute interactions play an important role in the sorption/desorption of AO7. Significant differences were observed in a desorption behavior of inorganic salts, whereas the solution of $\mathrm{NaCl}$ exhibited an even slightly lower desorption efficiency than pure water (maybe because of some 


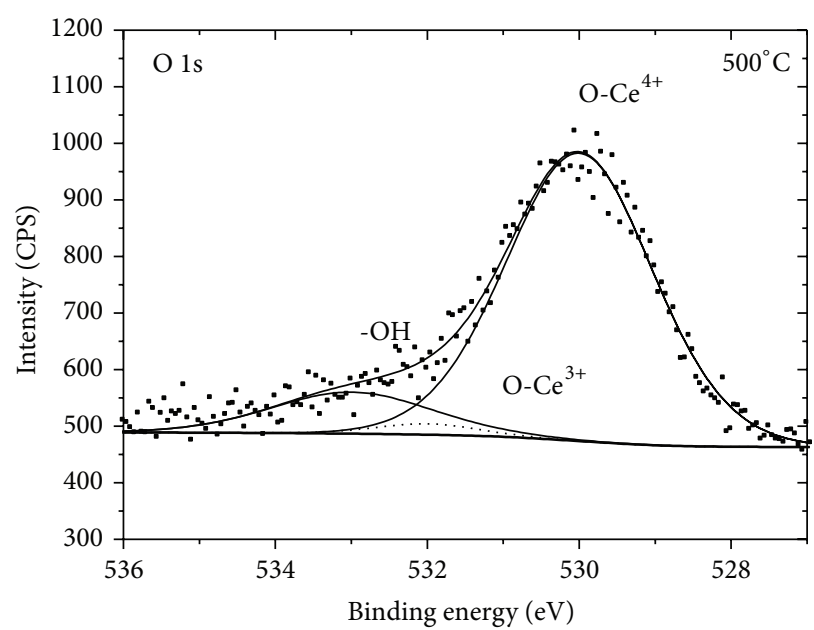

(a)

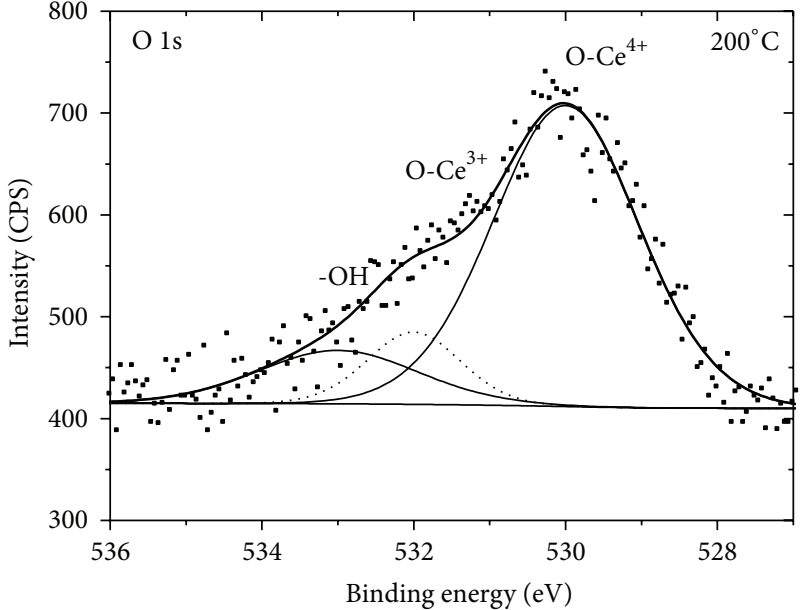

(b)

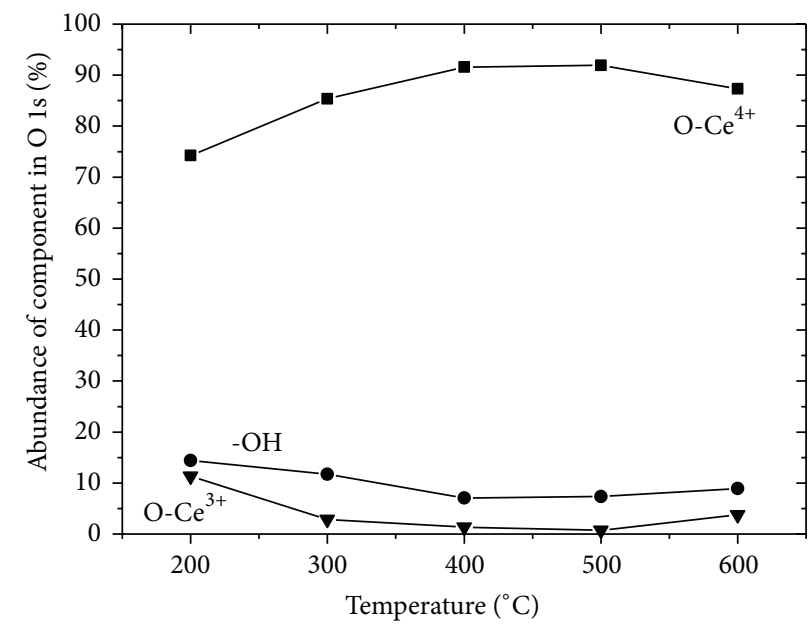

(c)

FIGURE 3: The oxygen $\mathrm{O} 1 \mathrm{~s}$ peak with three deconvoluted components for the samples prepared at the calcination temperature of $500^{\circ} \mathrm{C}(\mathrm{a})$ and $200^{\circ} \mathrm{C}$ (b); dependence of the abundances of $\mathrm{O} 1$ s components on the calcination temperature (c).

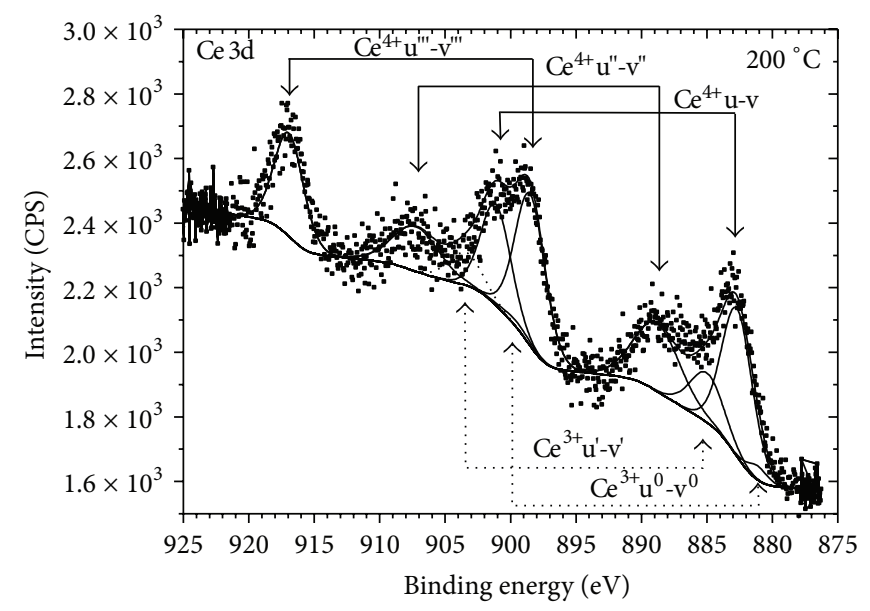

(a)



(b)

FIGURE 4: (a) The Ce 3d peak with deconvoluted components for the sample prepared at the calcination temperature of $200^{\circ} \mathrm{C}$. (b) Dependence of the abundances of the $\mathrm{Ce} 3 \mathrm{~d}$ components on the calcination temperature. 




FIGURE 5: The concentration of cerium (by square) and oxygen (by circle) in the samples on left axis and $\mathrm{O} / \mathrm{Ce}$ ratio with total oxygen (by full star-full line) and O/Ce ratio with only Ce bonded oxygen (by empty star-dot line) on right axis.

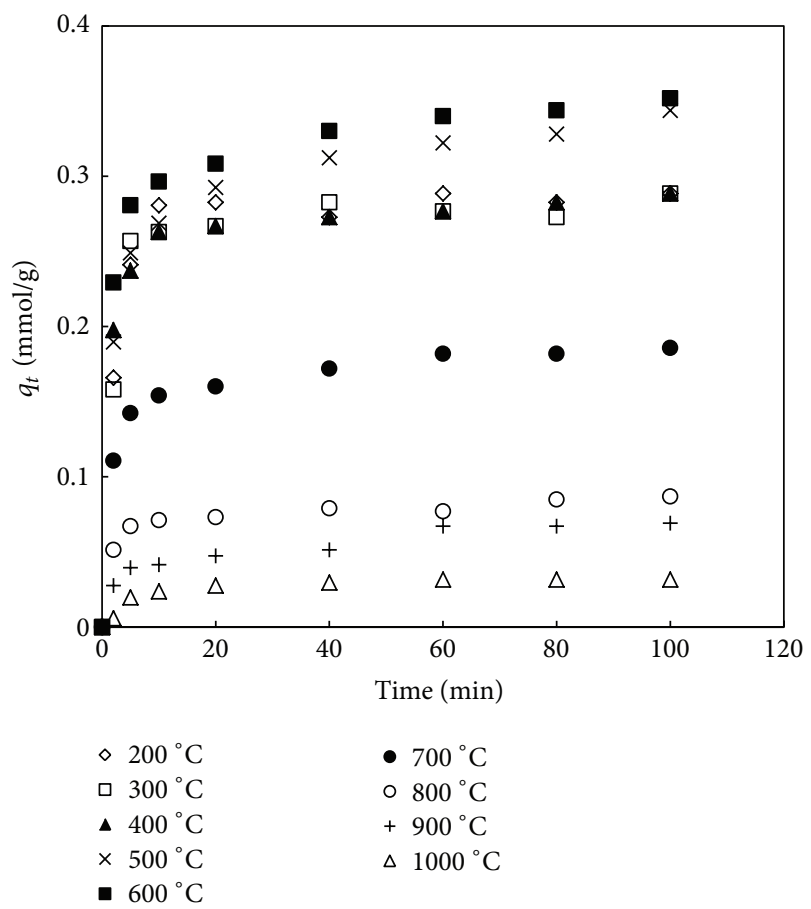

Figure 6: Kinetic dependencies for the sorption of $\mathrm{AO} 7$ on $\mathrm{CeO}_{2}$ annealed at different temperatures.

kind of a "salting out" effect); the $\mathrm{Na}_{2} \mathrm{SO}_{4}$ solution was by far most effective in the $\mathrm{AO} 7$ desorption from $\mathrm{CeO}_{2}$. Based on the experimental results and an analogy with the sorption of inorganic anions (sulphates) on metal oxide surfaces [23], it was suggested that specific hydrophilic interactions are responsible for the $\mathrm{AO} 7$ binding on $\mathrm{CeO}_{2}$, namely, the surface complexation, in which a sulphate group is involved.
The dye sorption and leaching with the sulphate solution may be described schematically as follows $(\mathrm{D}=$ dye):

$$
\begin{gathered}
>\mathrm{Ce}-\mathrm{OH}+\mathrm{H}_{2} \mathrm{O}+\mathrm{D}-\mathrm{SO}_{3}{ }^{-} \longleftrightarrow>\mathrm{Ce}-\mathrm{SO}_{3} \mathrm{D}+\mathrm{OH}^{-} \\
>\mathrm{Ce}-\mathrm{SO}_{3} \mathrm{D}+\mathrm{SO}_{4}{ }^{2-} \longleftrightarrow>\mathrm{CeOSO}_{3}{ }^{-}+\mathrm{D}-\mathrm{SO}_{3}{ }^{-}
\end{gathered}
$$

A simple representation of the dye sorption is given in Figure 9(a). In accordance with (4), the dye sorption is accompanied by a certain increase in $\mathrm{pH}$ (see Table 1). Equation (5) describes a competitive reaction between sulphate anion and a sulphonic group in the dye molecule for the binding sites on the oxide surface during desorption.

The surface hydroxyl groups play a significant role in the sorption process and determine the sorbent efficiency. When the sorbent is prepared by a precipitation/calcination route (as $\mathrm{CeO}_{2}$ from carbonate precursor), the number of hydroxyl groups may be affected by the conditions during the calcination step. Thermal decomposition of cerous carbonate on air is a rather complex process involving not only decarbonation and dehydration, but also oxidation of Ce(III) to $\mathrm{Ce}(\mathrm{IV})$. These reactions may occur simultaneously in a wide temperature range, but most of them are completed in the range of 200 to $300^{\circ} \mathrm{C}$. For oxy-carbonate $\mathrm{Ce}_{2} \mathrm{O}\left(\mathrm{CO}_{3}\right)_{2}$, the temperatures 200 and $235^{\circ} \mathrm{C}$ were reported for the removal of crystal water and $\mathrm{CO}_{2}$, respectively [24], whereas a somewhat higher temperature $\left(280^{\circ} \mathrm{C}\right)$ was reported for the decomposition of basic cerous carbonate $\mathrm{Ce}(\mathrm{OH}) \mathrm{CO}_{3}[25]$. We observed a continuously growing weight loss with increasing calcination temperature (from ca. $22 \%$ at $200^{\circ} \mathrm{C}$ to $25 \%$ at $800^{\circ} \mathrm{C}$ ) during calcination of the carbonate precursor under static conditions in an open crucible. It is assumed that the conversion of carbonate to cerium oxide took place at temperatures below $300^{\circ} \mathrm{C}$, but a complete dehydration requires high temperatures above $800^{\circ} \mathrm{C}$ [9], which may be related to the different contents of hydroxyl groups on the surface of sorbents prepared at different temperatures.

3.3. Degradation of Parathion Methyl on $\mathrm{CeO}_{2}$. Assuming that an efficiency of reactive sorbents depends on their surface chemistry, we examined the degradation of parathion methyl with cerium oxide samples exposed to various storage conditions, such as dry or wet air or acidic or basic vapors. Cerium oxide (the sample prepared by annealing at $500^{\circ} \mathrm{C}$ ) was placed on a Petri dish in a desiccator with adjusted atmosphere (see Table 3) for seven days, and subsequently its degradation efficiency was tested as described in the experimental section.

The degradation curves, that is, the time dependencies of the degradation of parathion methyl, are shown in Figure 10. As can be seen, the cerium oxide stored in dry atmosphere was rather effective in the destruction of parathion methyl; most of the pesticide disappeared in less than one hour and 4-nitrophenol (4-NP) was identified as the main degradation product. No other reaction product (e.g., paraoxon methyl) was positively detected at any stage of the degradation on any reactive sorbent. Changes in the 4-NP concentration with time are also shown in Figure 10. The PFO kinetic equation (2) was used to evaluate the time dependence for the 4-NP 


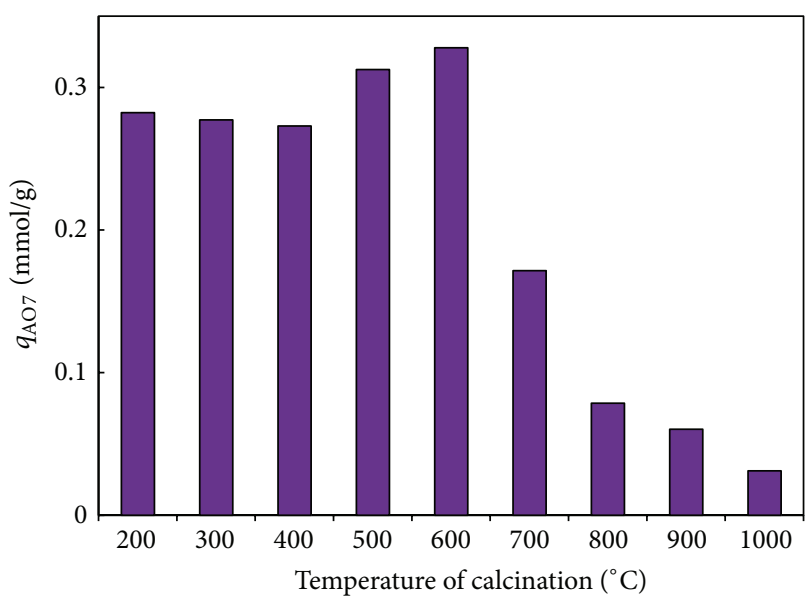

(a)

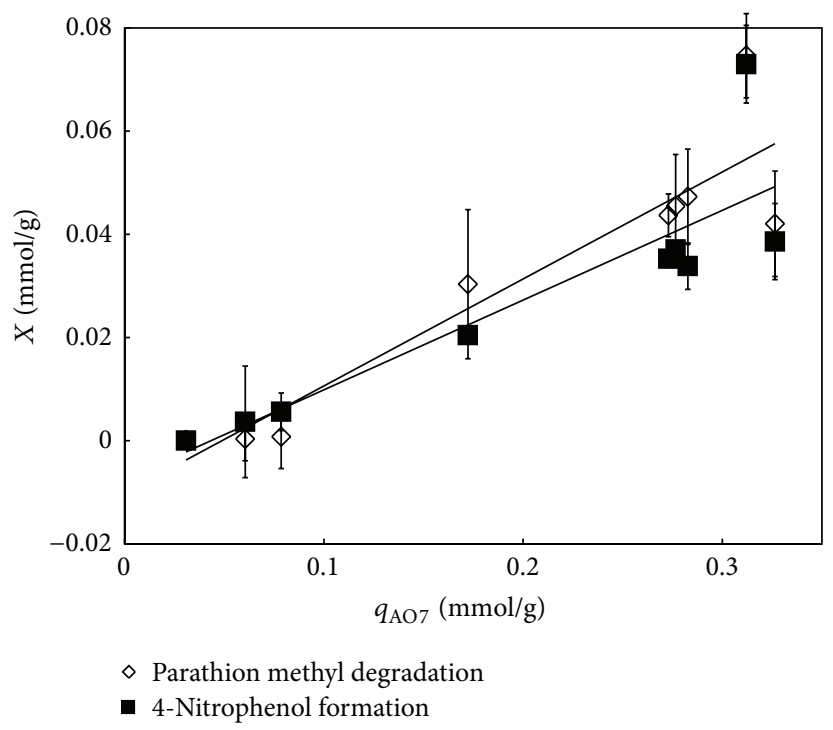

(b)

FIGURE 7: (a) Dependence of the sorption efficiency of $\mathrm{CeO}_{2}$ on the calcination temperature. (b) Correlation between sorption efficiency towards AO7 and degradation efficiency towards parathion methyl (data from [17]). Degradation efficiency expressed i terms of parathion disappearance (open diamonds) and formation of 4-nitrophenol (black squares) as the main degradation product.

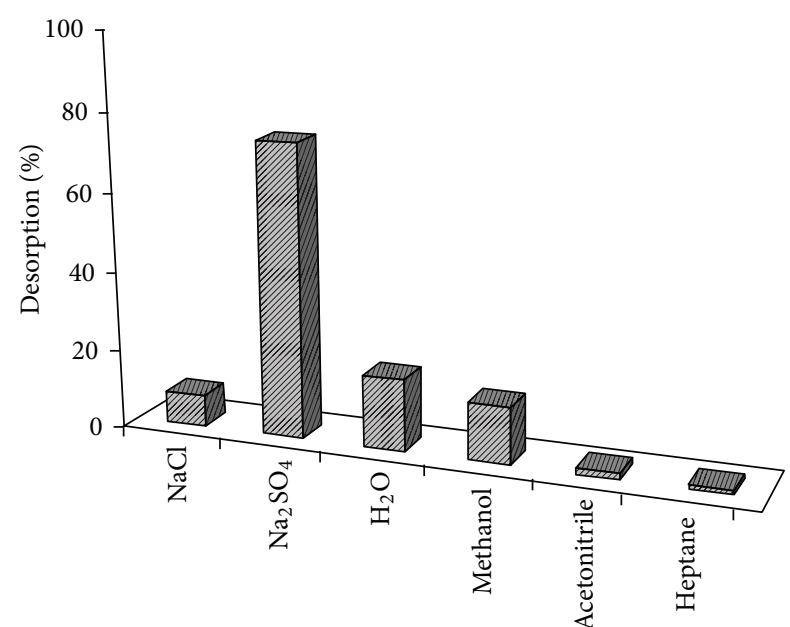

Figure 8: Desorption of $\mathrm{AO} 7$ from $\mathrm{CeO}_{2}$ with various leaching agents. $0.2 \mathrm{~g}$ of the loaded sorbent leached with $20 \mathrm{~mL}$ of the respective agent, concentration of $\mathrm{NaCl}$, and $\mathrm{Na}_{2} \mathrm{SO}_{4} 0.1 \mathrm{mmol} / \mathrm{L}$.

formation, whereas its modified form was used to evaluate the time dependence for the parathion methyl degradation as follows:

$$
q_{t}=q_{1} e^{-k_{1}^{*} t}+q_{\infty}^{*}
$$

In this equation, $q$ are dimensionless fractions of the reactant with respect to its initial amount: $q_{t}$ represents a residual quantity of the parathion methyl at time $t ; q_{1}$ is the fraction of parathion methyl degraded during the experiment; $q_{\infty}^{*}$ is the residual fraction of parathion methyl at the end of the reaction, if the destructive capacity of the reactive sorbent was not sufficient for complete degradation; $k_{1}^{*}$ is the degradation
TABLE 3: Storage conditions.

\begin{tabular}{lc}
\hline Storage conditions & In short \\
\hline $\mathrm{CeO}$ stored in a desiccator over solid & Dry air \\
$\mathrm{KOH}$ & ca. $50 \%$ humidity \\
$\mathrm{CeO}_{2}$ stored over saturated solution of & \\
$\left.\mathrm{Mg} \mathrm{NO}_{3}\right)_{2}$ & ca. $95 \%$ humidity \\
$\mathrm{CeO}_{2}$ stored over saturated solution of & \\
$\mathrm{KNO}_{3}$ & $\mathrm{NH}_{3}$ vapors \\
$\mathrm{CeO}_{2}$ stored over concentrated & \\
$\mathrm{NH}_{4} \mathrm{OH}$ & Formic acid vapors \\
$\mathrm{CeO}_{2}$ stored over concentrated formic & \\
$\mathrm{acid}^{\mathrm{ceO}}$ & Wet $\mathrm{CO}_{2}$ \\
$\left.\mathrm{Mg}_{2} \mathrm{NO}_{3}\right)_{2}$ purged with $\mathrm{CO}_{2}$ (g) & \\
\hline
\end{tabular}

rate constant. Parameters of the kinetic dependencies are listed in Table 4.

As described above, the kinetics of the parathion methyl removal and 4-NP formation were fitted as independent processes. However, it is clear that the degree of pesticide degradation closely correlated with the 4-NP formation, and a plausible correlation was also found between the corresponding rate constants $k_{1}$ and $k_{1}^{*}$ and the half-times. A mass balance taking into account the (sum of the) concentrations of parathion methyl and 4-NP gave an overall recovery above $90 \%$ in most experiments. Thus, $4-\mathrm{NP}$ may be considered the main product of the parathion methyl degradation. Other (side) products (if any) occur in minor quantities; their presence was not positively proven but should not be excluded. 
<smiles>O=S(=O)([O-])c1ccc(/N=N/c2c(O)ccc3ccccc23)cc1</smiles>

(a)

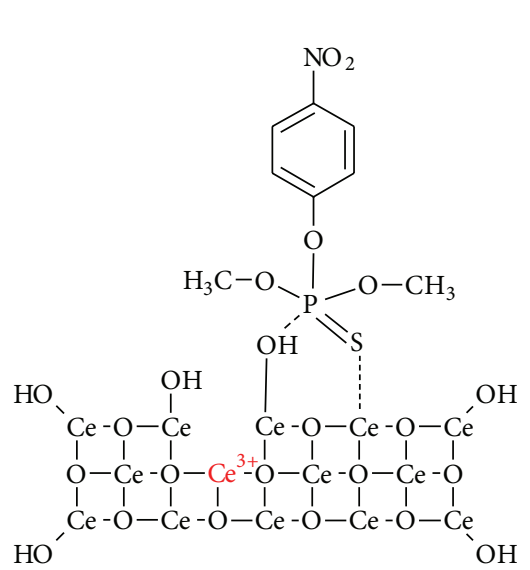

(b)

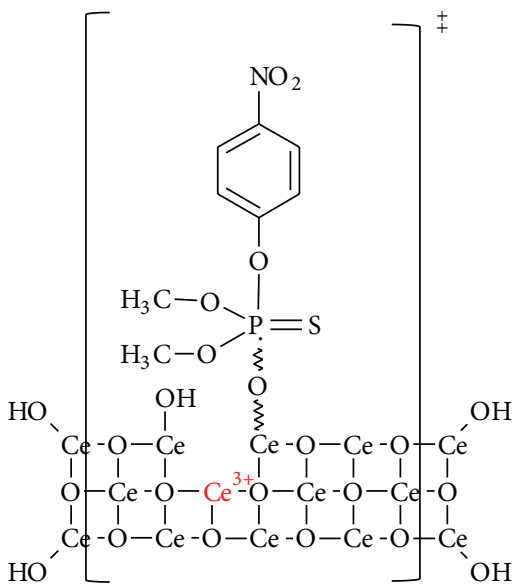

(c)

FIgURE 9: Interaction of $\mathrm{AO} 7$ with $\mathrm{CeO}_{2}$-surface complexation (a); interaction of parathion methyl with $\mathrm{CeO}_{2}$-formation of surface complex (b); interaction of parathion methyl with $\mathrm{CeO}_{2}$-nucleophilic attack, transition state (c).

TABLE 4: Parameters of kinetic curves for the degradation of parathion methyl (a) and creation of 4-nitrophenol (b).

(a) Degradation of parathion methyl

\begin{tabular}{|c|c|c|c|c|c|}
\hline Storage conditions for cerium oxide & $q_{\infty}^{* \mathrm{a}}$ & $k_{1}^{*}\left(\min ^{-1}\right)^{\mathrm{a}}$ & $t_{1 / 2}(\min )$ & $R^{2}$ & RSS \\
\hline $\mathrm{KNO}_{3}$ solution, ca. $95 \%$ humidity & $0.771(0.034)$ & $0.016(0.006)$ & 115.4 & 0.9569 & 0.0012 \\
\hline Solid $\mathrm{KOH}$, dry air & $0.151(0.067)$ & $0.047(0.017)$ & 40.9 & 0.8957 & 0.0490 \\
\hline Wet $\mathrm{CO}_{2}$ & $0.639(0.008)$ & $0.032(0.002)$ & 290.6 & 0.9962 & 0.0004 \\
\hline $\mathrm{Mg}\left(\mathrm{NO}_{3}\right)_{2}$ solution, ca. $50 \%$ humidity & $0.623(0.018)$ & $0.027(0.004)$ & 168.8 & 0.9862 & 0.0014 \\
\hline Vapors of formic acid & $0.983(0.007)$ & $\mathrm{N}$ & $\mathrm{N}$ & $\mathrm{N}$ & $\mathrm{N}$ \\
\hline $\mathrm{NH}_{3}$ vapors & $0.717(0.022)$ & $0.045(0.014)$ & 49.4 & 0.9230 & 0.0052 \\
\hline
\end{tabular}

(b) Creation of 4-nitrophenol

\begin{tabular}{lccccc}
\hline Storage conditions for cerium oxide & $q_{\infty}{ }^{\mathrm{a}}$ & $k_{1}\left(\mathrm{~min}^{-1}\right)^{\mathrm{a}}$ & $t_{1 / 2}(\mathrm{~min})$ & $R^{2}$ & $\mathrm{RSS}$ \\
\hline $\mathrm{KNO}_{3}$ solution, ca. 95\% humidity & $0.170(0.017)$ & $0.023(0.006)$ & 124.9 & 0.9543 & 0.0010 \\
Solid $\mathrm{KOH}$, dry air & $0.833(0.066)$ & $0.069(0.021)$ & 33.1 & 0.8720 & 0.0771 \\
Wet $\mathrm{CO}_{2}$ & $0.288(0.006)$ & $0.035(0.002)$ & 286.4 & 0.9953 & 0.0004 \\
$\mathrm{Mg}\left(\mathrm{NO}_{3}\right)_{2}$ solution, ca. 50\% humidity & $0.401(0.046)$ & $0.019(0.005)$ & 132.5 & 0.9553 & 0.0053 \\
Vapors of formic acid & $\mathrm{N}$ & $\mathrm{N}$ & $\mathrm{N}$ & $\mathrm{N}$ & $\mathrm{N}$ \\
$\mathrm{NH}_{3}$ vapors & $0.278(0.019)$ & $0.025(0.005)$ & 153.7 & 0.9747 & 0.0017 \\
\hline
\end{tabular}

${ }^{a}$ Standard errors given in parentheses; N: not determined.

The degrees of conversion of parathion methyl are compared in Figure 11. The highest degradation efficiency exhibited the cerium oxide sample stored in dry air, whereas the degradation efficiency of the samples stored in wet air (50 and 95\% humidity) and wet air saturated with $\mathrm{CO}_{2}$ was markedly lower and mutually comparable. This is consistent with our previous finding that the degradation is inhibited in water and other protic solvents [17]. It should be pointed out that the $\mathrm{CeO}_{2}$ samples stored under ambient conditions (in closed PE bottle in the laboratory for more than six months, with intermittent openings) exhibited even higher efficiency than the sample stored in dry air over $\mathrm{KOH}$ (cf. [17]). It was suggested that the organophosphate degradation in the presence of cerium oxide is governed by the $\mathrm{S}_{\mathrm{N}} 2$ mechanism (a nucleophilic substitution, in which the $-\mathrm{OH}$ groups on the sorbent surface attack the $\mathrm{P}$ atom in the parathion methyl molecule); 4-nitrophenol is liberated as a leaving group. Small amounts of water promote the formation of -OH groups on the cerium oxide surface; it was confirmed that the formation of these groups is energetically favourable especially in the vicinity of oxygen vacancies associated with the presence of nonstoichiometric "impurities," such as $\mathrm{Ce}^{3+}$ cations [26]. When a large amount of water is present (high humidity, aqueous solvent as a reaction medium), the water molecules compete with the pesticide molecules for the active sites forming intermolecular hydrogen bonds with the surface 


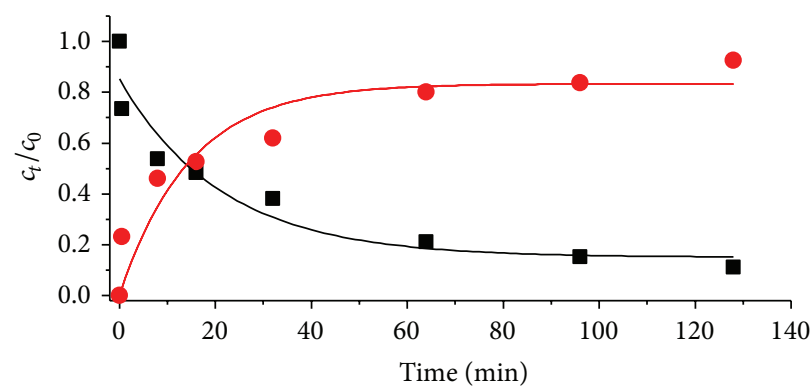

(a) Solid $\mathrm{KOH}$, dry air

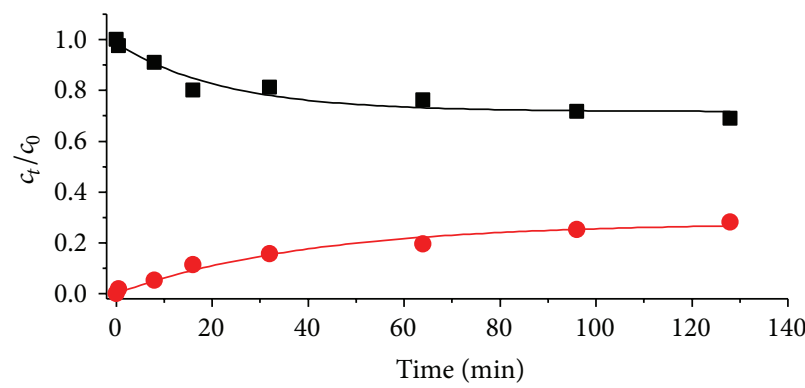

(c) $\mathrm{NH}_{3}$ vapors

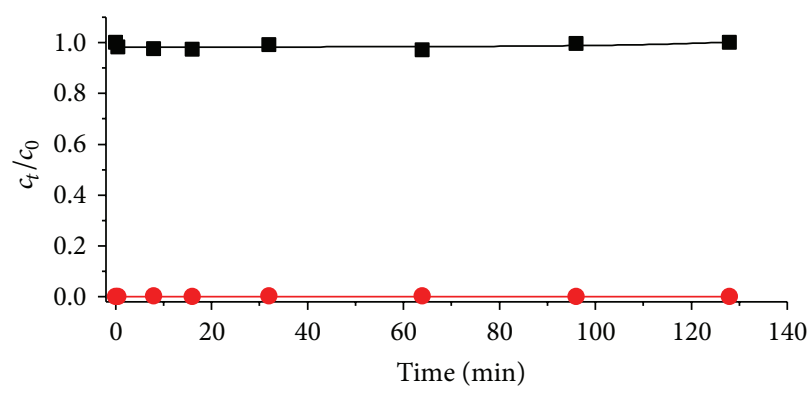

Parathion methyl

4-Nitrophenol

(e) Formic acid vapors

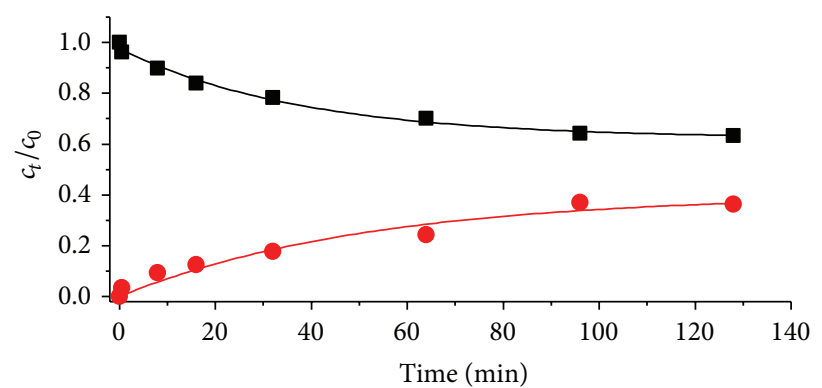

(b) $\mathrm{Mg}\left(\mathrm{NO}_{3}\right)_{2}$ solution, ca. $50 \%$ humidity

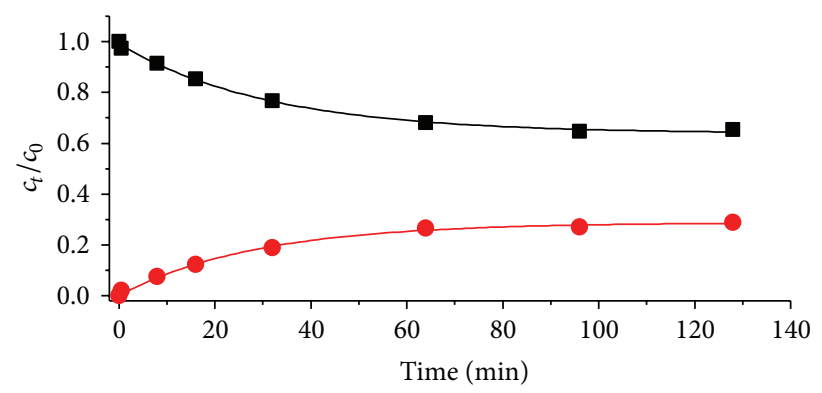

(d) Wet $\mathrm{CO}_{2}$

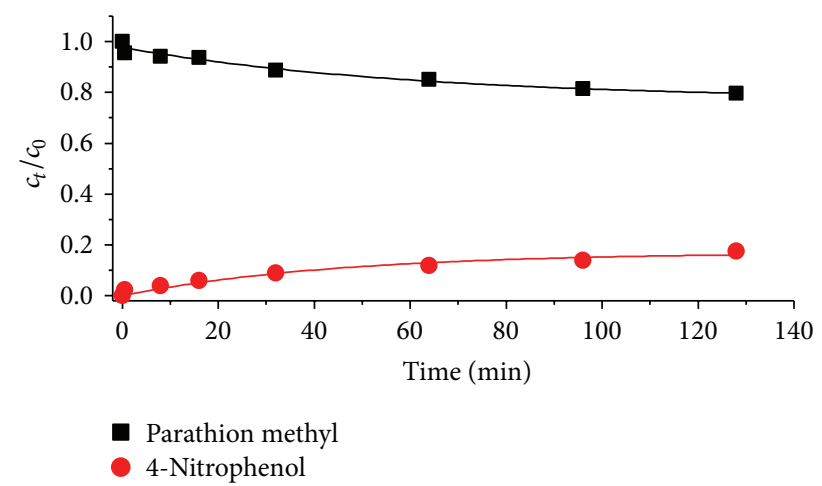

(f) $\mathrm{KNO}_{3}$ solution, ca. $95 \%$ humidity

Figure 10: Degradation of parathion methyl with cerium oxide stored in dry air (a), wet air with $50 \%$ humidity (b), $\mathrm{NH}_{3}$ vapors (c), wet $\mathrm{CO}_{2}$ (d), formic acid vapors (e), and wet air with 95\% humidity (f).

hydroxyl groups and thus prevent the degradation reaction. Molecules of formic acid are even more effective in blocking the degradation reaction, as they cause a protonation of the surface hydroxyl groups that lose their nucleophilic nature in this way. Under optimum conditions, the organophosphate degradation on cerium oxide may be supported by the formation of surface complexes with the $\mathrm{Ce}^{4+}\left(\mathrm{Ce}^{3+}\right)$ cations similarly as in solution [27]. The respective intermediate and transition states are depicted in Figure 8.

\subsection{Correlation between Sorption Ability and Degradation} Efficiency. Both adsorption of $\mathrm{AO} 7$ and degradation of parathion methyl were examined using a series of the cerium oxide sorbents with various efficiencies in dependence on the calcination temperature used during the sorbent preparation. We have noticed that the temperature dependence for the AO7 sorption as shown in Figure 7 (a) was very similar to that observed in the case of the parathion methyl degradation on the same sorbents, as studied in [17]. In both cases, the maximum efficiency was achieved with the samples annealed at $500^{\circ} \mathrm{C}$, whereas the samples annealed at high temperatures above $700^{\circ} \mathrm{C}$ were nearly ineffective. It is demonstrated in Figure 7 (b) that the sorption efficiency for AO7 correlates closely with the degradation efficiency for organophosphate pesticide parathion methyl on the same sorbents, despite the fact that both processes proceeded in quite different media (water versus heptane). It is, on the other hand, difficult to find a simple correlation between the sorption/degradation efficiency of the sorbents and their physicochemical characteristics. Undoubtedly, the decrease of the specific surface area with increasing calcination temperature may be related to the dramatic decrease in the efficiency of the sorbents annealed at temperatures above $600^{\circ} \mathrm{C}$. This process was accompanied also by a successive reduction of the micropore surface area; whereas the micropore surface area was about 


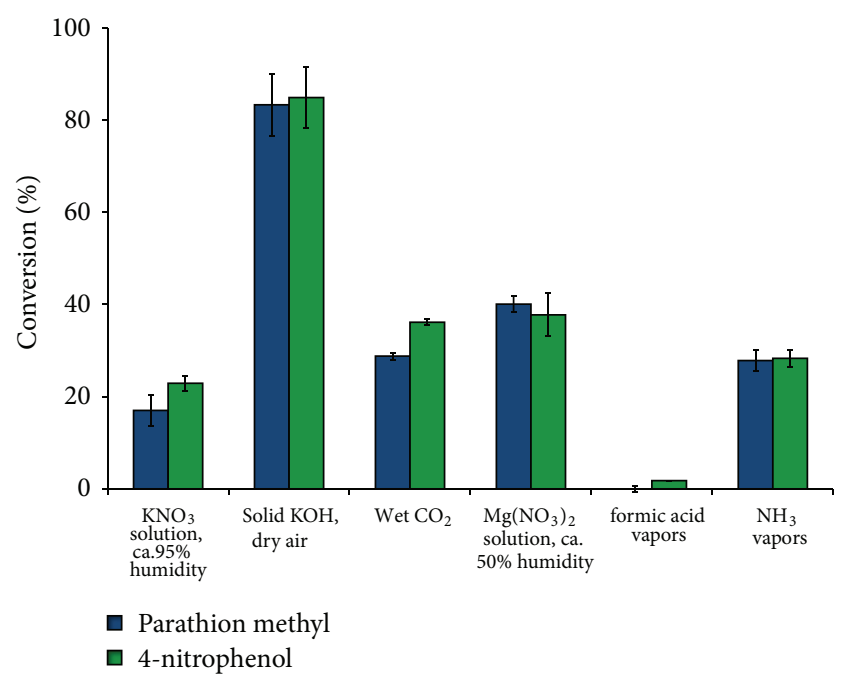

FIGURE 11: Degree of conversion of parathion methyl to 4nitrophenol using the $\mathrm{CeO}_{2}$-based reactive sorbents stored under various conditions. Calculated from the $q_{\infty}$ values in Table 4 .

$6.5 \mathrm{~m}^{2} / \mathrm{g}$ for the sample annealed at $200^{\circ} \mathrm{C}$, it dropped to $1.8 \mathrm{~m}^{2} / \mathrm{g}$ for the sample annealed at $500^{\circ} \mathrm{C}$; the micropores disappeared completely at higher temperatures. The XRD measurement demonstrated clearly that the crystalline structure becomes more ordered with increasing calcination temperature, making the formation of the crystal defects (potential active sites) less probable. There are, however, also some processes with an opposite trend, such as oxidation of cerium with increasing temperature. Two main temperaturedependent effects governing the surface properties of cerium oxide, namely, the transformation of $\mathrm{Ce}^{3+}$ to $\mathrm{Ce}^{4+}$ and the formation of oxygen vacancies $[28,29]$, are related to the presence of crystal defects and surface hydroxyl groups possibly serving as active centres in catalytic and adsorption processes. Most probably, the high activity of the sorbents prepared at moderate temperatures of about $500^{\circ} \mathrm{C}$ was a result of a combination of several partly opposing trends; both physical parameters and surface chemistry should be taken into account during an optimization of the sorbent preparation.

\section{Conclusions}

Properties of cerium oxide prepared from the carbonate precursor are strongly affected by the temperature during the calcination. The highest sorption efficiency towards AO7 exhibited sorbents prepared at temperatures below $700^{\circ} \mathrm{C}$, which was attributed mainly to the presence of hydroxyl groups on the $\mathrm{CeO}_{2}$ surface. It was hypothesized that they are involved in the binding of AO7 by a surface-complexation mechanism. Surface hydroxyl groups belong also to the most active sites responsible for the degradation of highly toxic organophosphate compounds with metal oxides as reactive sorbents [30]. In this work, we demonstrated a strong correlation between an adsorption efficiency of cerium oxides and their degradation efficiency for organophosphate pesticide parathion methyl. As the ceria-based sorbents exhibited a strong affinity towards the phosphorus-containing compounds [31], it is believed that the findings in this work will be helpful in designing new kinds of reactive sorbents for the CWAs decontamination.

\section{Conflict of Interests}

The authors declare that there is no conflict of interests regarding the publication of this paper.

\section{Acknowledgments}

Financial support from the Czech Science Foundation (Grant no. P106/12/1116) is gratefully acknowledged. Dr. Petr Ryšánek from the Research Institute of Inorganic Chemistry, Usti nad Labem, is thanked for X-ray diffraction measurements.

\section{References}

[1] N. K. Renuka, A. K. Praveen, and C. U. Aniz, "Ceria rhombic microplates: synthesis, characterization and catalytic activity," Microporous and Mesoporous Materials, vol. 169, pp. 35-41, 2013.

[2] C.-H. Wang and S.-S. Lin, "Preparing an active cerium oxide catalyst for the catalytic incineration of aromatic hydrocarbons," Applied Catalysis A: General, vol. 268, no. 1-2, pp. 227-233, 2004.

[3] C. A. Orge, J. J. M. Órfão, M. F. R. Pereira, A. M. D. de Farias, R. C. R. Neto, and M. A. Fraga, "Ozonation of model organic compounds catalysed by nanostructured cerium oxides," Applied Catalysis B: Environmental, vol. 103, no. 1-2, pp. 190-199, 2011.

[4] Y. Zhai, S. Zhang, and H. Pang, "Preparation, characterization and photocatalytic activity of $\mathrm{CeO}_{2}$ nanocrystalline using ammonium bicarbonate as precipitant," Materials Letters, vol. 61, no. 8-9, pp. 1863-1866, 2007.

[5] S. B. Khan, M. Faisal, M. M. Rahman, and A. Jamal, "Exploration of $\mathrm{CeO}_{2}$ nanoparticles as a chemi-sensor and photocatalyst for environmental applications," Science of the Total Environment, vol. 409, no. 15, pp. 2987-2992, 2011.

[6] P. Ji, J. Zhang, F. Chen, and M. Anpo, "Study of adsorption and degradation of acid orange 7 on the surface of $\mathrm{CeO}_{2}$ under visible light irradiation," Applied Catalysis B: Environmental, vol. 85, no. 3-4, pp. 148-154, 2009.

[7] A. Asati, S. Santra, C. Kaittanis, S. Nath, and J. M. Perez, "Oxidase-like activity of polymer-coated cerium oxide nanopartieles," Angewandte Chemie-International Edition, vol. 48, no. 13, pp. 2308-2312, 2009.

[8] V. K. Ivanov, A. B. Shcherbakov, and A. V. Usatenko, "Structuresensitive properties and biomedical applications of nanodispersed cerium dioxide," Russian Chemical Reviews, vol. 78, no. 9, pp. 855-871, 2009.

[9] V. D. Kosynkin, A. A. Arzgatkina, E. N. Ivanov et al., "The study of process production of polishing powder based on cerium dioxide," Journal of Alloys and Compounds, vol. 303-304, pp. 421-425, 2000.

[10] G. A. Silva, "Nanomedicine: seeing the benefits of ceria," Nature Nanotechnology, vol. 1, no. 2, pp. 92-94, 2006.

[11] E. Mercadelli, G. Ghetti, A. Sanson, R. Bonelli, and S. Albonetti, "Synthesis of $\mathrm{CeO}_{2}$ nano-aggregates of complex morphology," Ceramics International, vol. 39, no. 1, pp. 629-634, 2013. 
[12] K. Kaneko, K. Inoke, B. Freitag et al., "Structural and morphological characterization of cerium oxide nanocrystals prepared by hydrothermal synthesis," Nano Letters, vol. 7, no. 2, pp. 421425, 2007.

[13] A. C. Cabral, L. S. Cavalcante, R. C. Deus, E. Longo, A. Z. Simoes, and F. Moura, "Photoluminescence properties of praseodymium doped cerium oxide nanocrystals," Ceramics International, vol. 40, no. 3, pp. 4445-4453, 2014.

[14] X. Dong, L. Ming L, Z. Wei, L. Guixia, and H. Guangyan, "Preparation and characterization of nanocrystalline $\mathrm{CeO}_{2}$ by precipitation method," Journal of Rare Earths, vol. 20, no. 6, pp. 583-586, 2002.

[15] R. Suresh, V. Ponnuswamy, and R. Mariappan, "Effect of annealing temperature on the microstructural, optical and electrical properties of $\mathrm{CeO}_{2}$ nanoparticles by chemical precipitation method," Applied Surface Science, vol. 273, pp. 457-464, 2013.

[16] M. Li, Z. Liu, Y. Hu, Z. Shi, and H. Li, "Effects of the synthesis methods on the physicochemical properties of cerium dioxide powder," Colloids and Surfaces A: Physicochemical and Engineering Aspects, vol. 301, no. 1-3, pp. 153-157, 2007.

[17] P. Janoš, P. Kuráň, M. Kormunda et al., "Cerium dioxide as a new reactive sorbent for fast degradation of parathion methyl and some other organophosphates," Journal of Rare Earths, vol. 32, no. 4, pp. 360-370, 2014.

[18] M. Brigante and P. C. Schulz, "Cerium(IV) oxide: synthesis in alkaline and acidic media, characterization and adsorption properties," Chemical Engineering Journal, vol. 191, pp. 563-570, 2012.

[19] M. F. L. Johnson and J. Mooi, "Cerium dioxide crystallite sizes by temperature-programmed reduction," Journal of Catalysis, vol. 103 , no. 2, pp. 502-505, 1987.

[20] P. Janoš, S. Hejda, E. Agapovová, and J. Fikarová, “Determination of sulfonated azo dyes by ion-interaction chromatography in reversed-phase system," Chemicke Listy, vol. 105, no. 12, pp. 943-947, 2011.

[21] K. Momma and F. Izumi, "VESTA 3 for three-dimensional visualization of crystal, volumetric and morphology data," Journal of Applied Crystallography, vol. 44, no. 6, pp. 1272-1276, 2011.

[22] W. Plazinski, W. Rudzinski, and A. Plazinska, “Theoretical models of sorption kinetics including a surface reaction mechanism: a review," Advances in Colloid and Interface Science, vol. 152, no. 1-2, pp. 2-13, 2009.

[23] D. A. Sverjensky and K. Fukushi, "Anion adsorption on oxide surfaces: inclusion of the water dipole in modeling the electrostatics of ligand exchange," Environmental Science and Technology, vol. 40, no. 1, pp. 263-271, 2006.

[24] N. Afify, A. S. Abdel-Halim, and S. M. El-Hout, "Thermal and X-ray analysis of cerium oxy-carbonate," Journal of Thermal Analysis, vol. 34, no. 1, pp. 189-194, 1988.

[25] F. Hrizi, H. Dhaouadi, and F. Touati, "Cerium carbonate hydroxide and ceria micro/nanostructures: synthesis, characterization and electrochemical properties of $\mathrm{CeCO}_{3} \mathrm{OH}$,' Ceramics International, vol. 40, no. 1, pp. 25-30, 2014.

[26] S. Hayun, T. Y. Shvareva, and A. Navrotsky, "Nanoceriaenergetics of surfaces, interfaces and water adsorption," Journal of the American Ceramic Society, vol. 94, no. 11, pp. 3992-3999, 2011.

[27] V. Naik and C. P. Shinde, "Degradation of organophosphorus compounds by hydrolysis in presence of metal cations," Science Technology \& Management Journal. In press, http://www.aisectuniversity.ac.in/Anushandhan3.aspx.
[28] P. Dutta, S. Pal, M. S. Seehra, Y. Shi, E. M. Eyring, and R. D. Ernst, "Concentration of $\mathrm{Ce}^{3+}$ and oxygen vacancies in cerium oxide nanoparticles," Chemistry of Materials, vol. 18, no. 21, pp. 5144-5146, 2006.

[29] J. Kullgren, Oxygen Vacancy Chemistry in Ceria, Acta Universitatis Upsaliensis, Uppsala, Sweden, 2012.

[30] N. Sharma and R. Kakkar, "Recent advancements on warfare agents/metal oxides surface chemistry and their simulation study," Advanced Materials Letters, vol. 4, no. 7, pp. 508-521, 2013.

[31] G. Cheng, J.-L. Zhang, Y.-L. Liu, D.-H. Sun, and J.-Z. Ni, "Synthesis of novel $\mathrm{Fe}_{3} \mathrm{O}_{4} @ \mathrm{SiO}_{2} @ \mathrm{CeO}_{2}$ microspheres with mesoporous shell for phosphopeptide capturing and labeling," Chemical Communications, vol. 47, no. 20, pp. 5732-5734, 2011. 

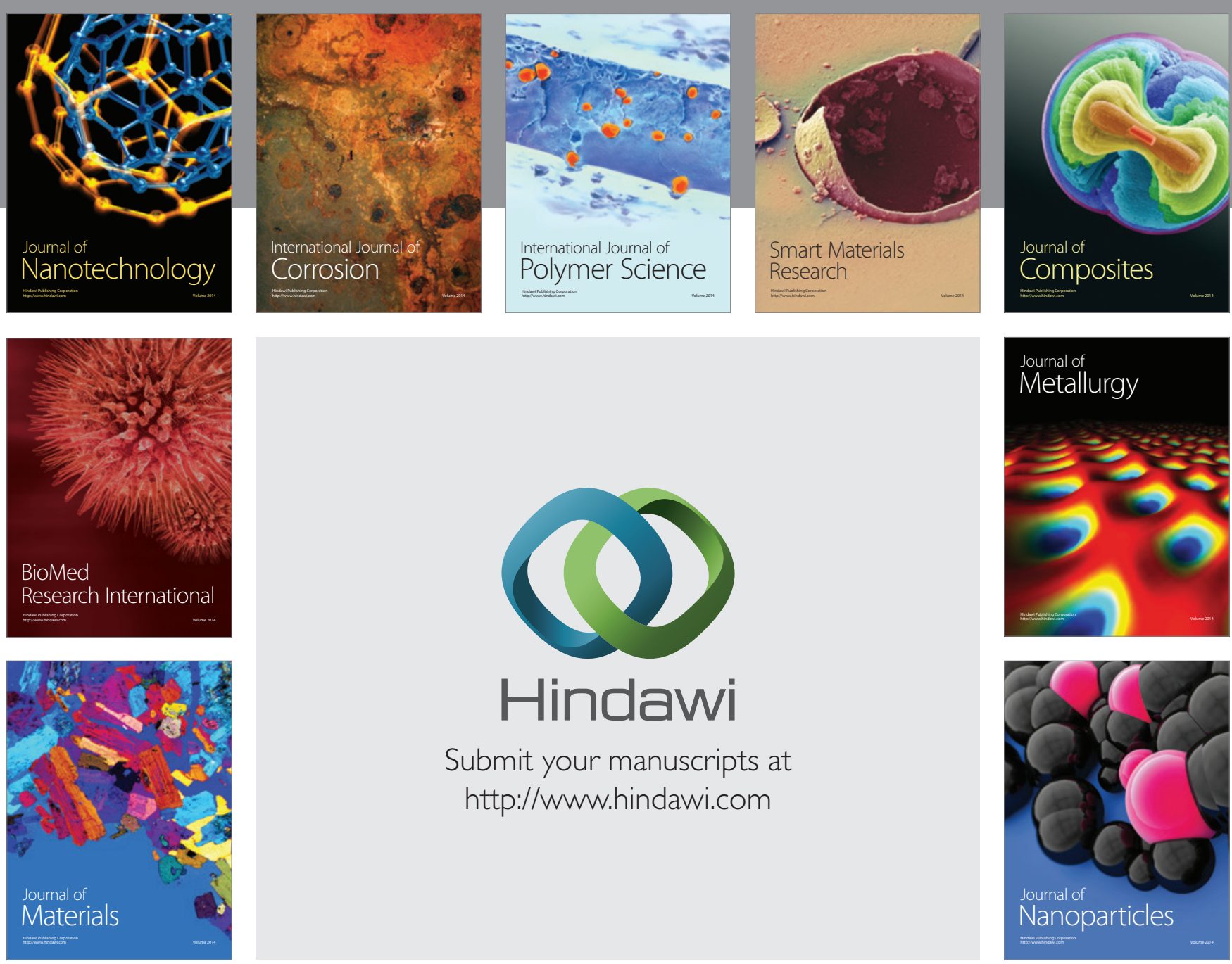

Submit your manuscripts at http://www.hindawi.com
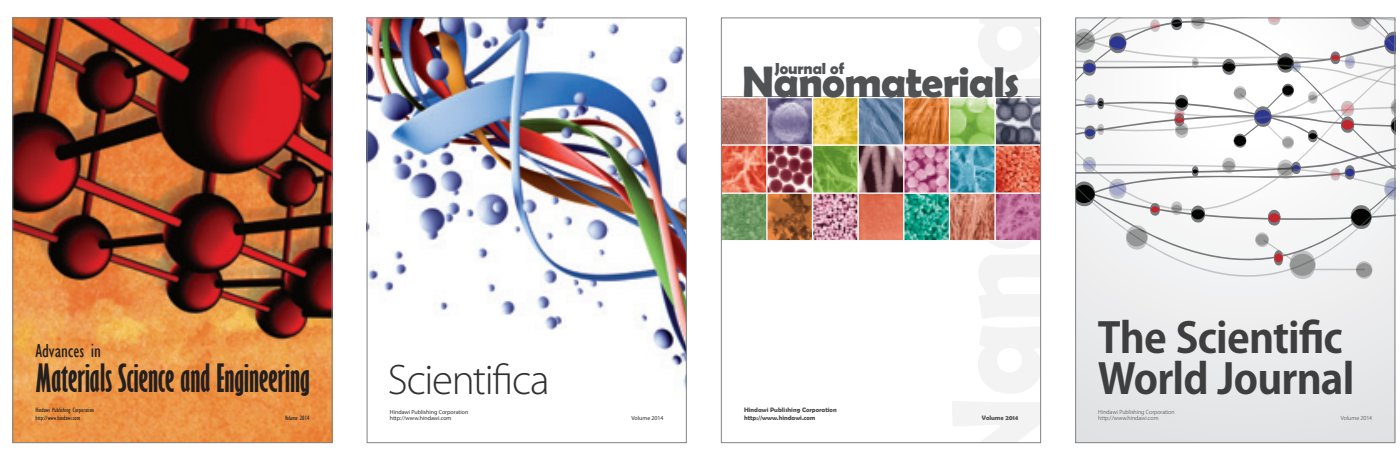

\section{The Scientific World Journal}
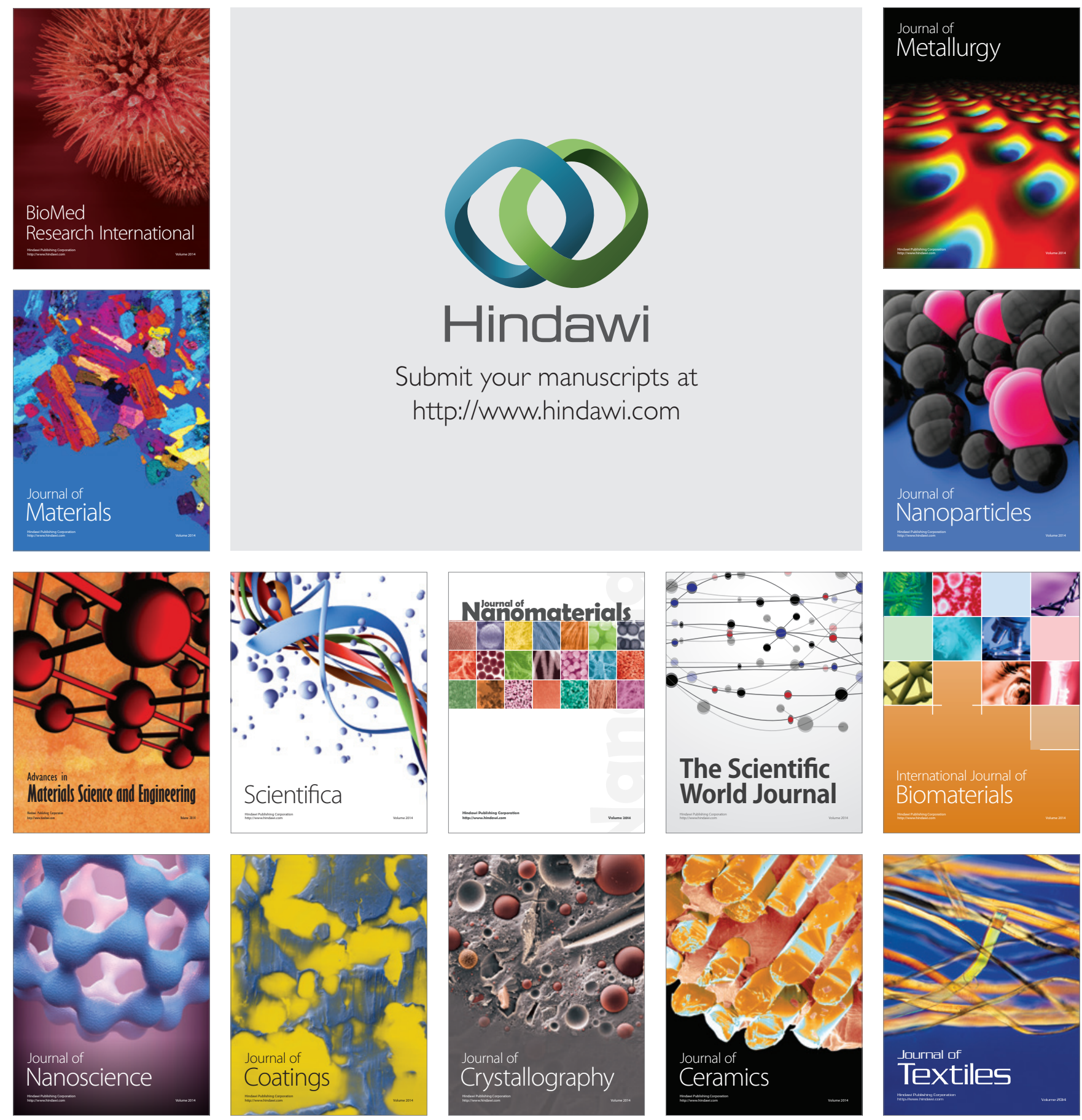